\title{
A Case Study of Enhancing Sustainable Intensification of Chinese Torreya Forest in Zhuji of China
}

\author{
Xiongwen Chen ${ }^{1,2}$ \& Hangbiao $\mathrm{Jin}^{3}$ \\ ${ }^{1}$ Department of Biological \& Environmental Sciences, Alabama A \& M University, Normal, AL 35762, USA \\ ${ }^{2}$ Department of Landscape \& Art, Jiyang College of Zhejiang A \& F University, Zhuji, P. R. China \\ ${ }^{3}$ Zhuji Academy of Forestry, Zhuji City, Zhejiang Province, P. R. China \\ Corresponding: Xiongwen Chen, Department of Biological \& Environmental Sciences, Alabama A \& M \\ University, Normal, AL 35762, USA. Tel: 256-372-4231. E-mail: xiongwen.chen@aamu.edu
}

Received: April 11, 2019

Accepted: April 26, 2019

Online Published: May 5, 2019

doi:10.5539/enrr.v9n2p53

URL: https://doi.org/10.5539/enrr.v9n2p53

\begin{abstract}
Chinese torreya (Torreya grandis cv. Merrillii) is an important cash tree in southeastern China and this species plays a major role in local economy. Establishing new plantations of Chinese torreya would be necessary in order to receive more economic benefit. However, expanding the area of torreya plantations would conflict with other land-use and also affect regional biodiversity. Under this context, local people and government made a paradigm shift from nuts productivity to sustainable practices. They explored the multi-functionalities of Chinese torreya forests, such as the social, cultural, environmental and health functionalities, and developed ecotourism as a breakthrough. The development of multi-functionalities of torreya plantations greatly improved the local economy and led a success in the local society. The strategy of this case completely followed the principles of sustainable intensification of agriculture and translational ecology, which involve scientists, stakeholders and policy makers to emphasize landscape multi-functionalities and minimize environmental impacts of operations. The knowledge from this study may be helpful to research in other regions.
\end{abstract}

Keywords: economy, land-use, multi-functionalities, paradigm shift, translational ecology

\section{Introduction}

Agriculture is mainly to provide sufficient food for the growing human population, which is predicted to require an increase of global food about $60 \sim 110 \%$ by 2050 (Foley et al., 2005; Pardey, Beddow, Hurley, Beatty, \& Eidman, 2014). In mountainous areas, more people experienced food insecurity and poverty than at lowland areas due to limited agricultural land (Gratzer \& Keeton, 2017). However, agriculture is also the largest driver of global environmental change, such as biodiversity loss, water pollution and emissions of greenhouse gases (Tilman et al., 2001; Foley et al., 2005; Steffen, Crutzen, \& McNeil, 2007). At the same time, agriculture is most affected by the global change (IPCC, 2014), such as agriculture in mountainous areas. Thus, it is urgently required to shift the focus of agricultural development from productivity to sustainability, which means to reduce environmental impacts for attaining human development (United Nations Secretary, 2012; Rockström et al., 2017). Sustainable intensification of agriculture is to enhance agricultural productivity while reducing environmental impacts (e.g., water supply, gas emissions, and pollutions) (Conway, 1997; Godfray \& Garnett, 2014). To achieve this goal, agriculture needs to incorporate approach from landscape ecology, which smartly use ecological functionalities of natural ecosystems. The aim of sustainable intensification of agriculture is to develop multi-functional agroecosystems that are both sustained by nature and sustainable in their nature (Tittonell, 2014). Such a paradigm shift to sustainability needs to minimize environmental impacts but also raise productivity (Jackson et al., 2012; Rockström et al., 2017).

In order to address the challenges from social and environmental sustainability, ecologists need to use the strategy from translational ecology, which means ecologists, stakeholders, and decision makers work together to develop research involving sociological, ecological, and political contexts of environmental issues (Enquist et al., 2017). Particularly for vulnerable mountainous regions, where provide a vast array of goods and services to human society and are also sensitive to environmental change (Grêt-Regamey, Brunner, \& Kienast, 2012). Addressing the questions arising from the varied needs of end-users on-the-ground with different cultural contexts can foster the 
high levels of trust and commitment that are critical for long term, sustained engagement between partners (Enquist et al., 2017; Jackson, Garfin, \& Enquist, 2017; Wall, McNie, \& Garfin, 2017). Here culture is considered as all aspects of life (e.g., clothing, growing and preparing food, taking care of health, ceremonies and beliefs) (Belay, Edwards, \& Gebeyehu, 2005). The cultural significance of plant resources and shared knowledge could contribute to the engaged participation and joint decision-making for improving local economy (Shrestha \& Medley, 2017).

As a case study, Chinese torreya (Torreya grandis cv. Merrillii) is an important cash tree and a main source of income for the local farmers in southeastern China (Figure 1). It was developed from a quality grafted tree species through carefully artificial selecting in a long time ago (e.g., a thousand years ago) at Kuaiji Mountain area in China (Li \& Dai, 2007). Its products include nuts, medicine, logs, oil, and ornaments (Chen \& Jin, 2019). The processed nuts for snack food cost approximately $\$ 50 \sim 70$ per $\mathrm{kg}$. Usually one tree can bring in about $\$ 5,000$ from nuts while a local family may have $4 \sim 5$ trees. The two towns, Zhaojiazhen and Dongbaihu in Zhuji County (also called City), produce more than 1,000 tons of nuts every year and earn approximately $\$ 58$ million. More than 50,000 farmers got rid of poverty through planting this tree species and producing nuts (Chen \& Jin, 2019; People's Government of Shaoxing City, 2013). Chinese torreya tree has a narrow distribution in southeastern China (Li \& Dai, 2007). Kuaiji Mountain is the original place of Chinese torreya with the most well preserved ancient torreya tree community, which is about 1,500 years old (Wang and Ming 2015). More than 80\% of Chinese torreya production is from this region. With the increasing demand from market, more and more farmers would like to change their land-use and construct plantations of Chinese torreya (Figure 2). However, there are several problems have to be solved before creating new torreya plantations.
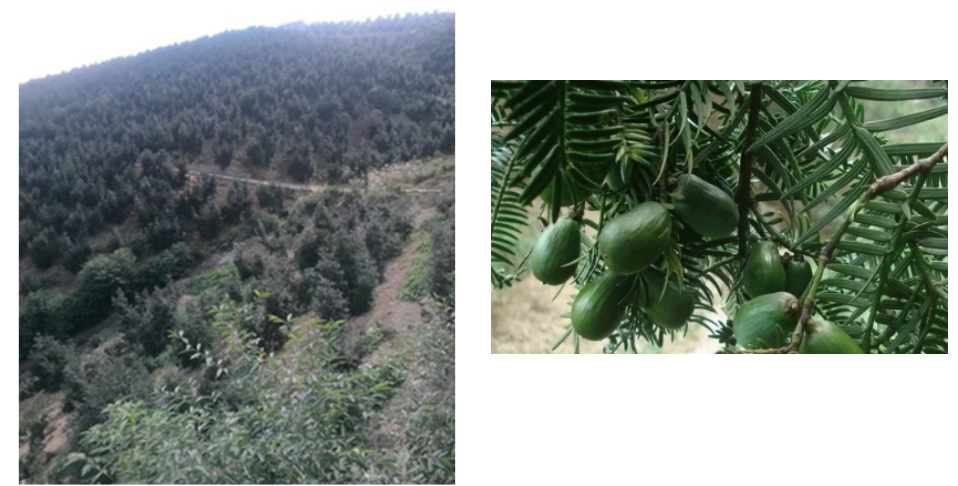

Figure 1. Chinese torreya forest and tree leaves and fruits.

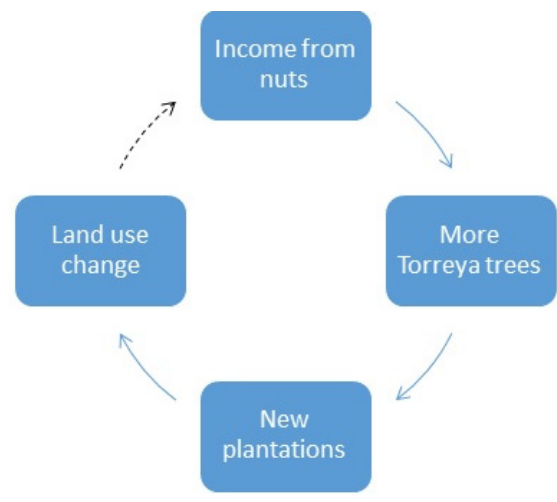

Figure 2. Traditional approach to increase the income from Chinese torreya forests through increasing plantation area (solid line with arrow means possible and dot line with arrow means uncertainty) 


\section{Some Issues to Create Plantations of Chinese Torreya}

- Land use conflict: The idea of creating more plantations of Chinese torreya will lead to local/regional conflicting in land-use. During the past 10 years, the area of Chinese torreya plantations increased from approximately 5,333 hectares to 9,000 hectares at Zhuji County alone (Figure 3). Other land-use, such as crop land, tea garden, orchard, chest nut, bamboo forest, and Camellia garden, are also necessary for the life of local people. Natural forest ecosystems including both old forests and young forests are important for maintaining local biodiversity and ecological services (e.g., preventing soil erosion and providing carbon storage) although these services may not directly bring income to local people.

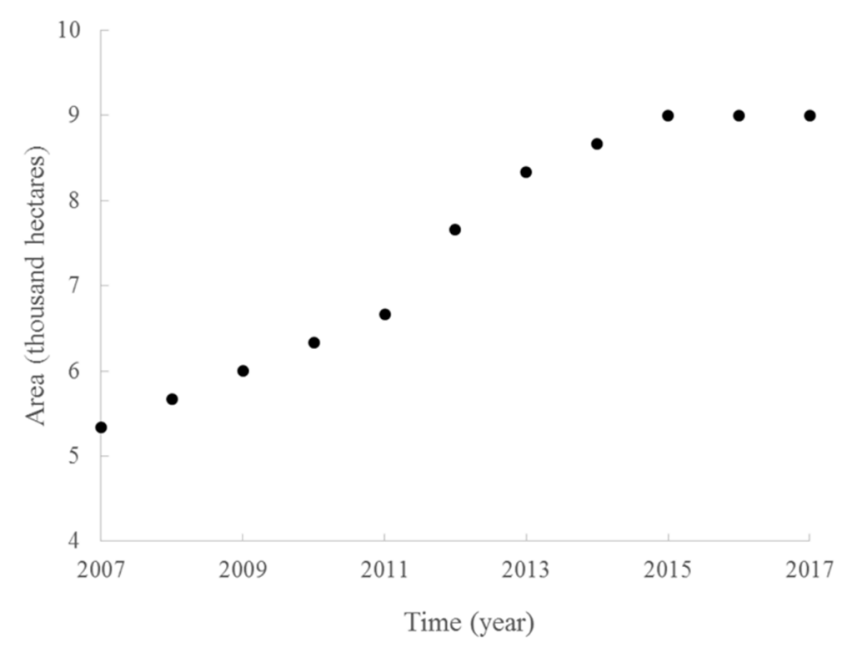

Figure 3. The total plantation area of Chinese torreya plantations at Zhuji in the past 10 years

- Long time investment: It usually takes about 10 20 years for young torreya trees to start seed production. During such a long time period there is only input but no profit. Large amount of financial support is needed to create new plantations (People's Government of Shaoxing City, 2013).

- Man power: It is a labor intensive job to construct plantations and manage Chinese torreya trees, including weeds controlling, seeds harvesting and nuts processing (Li \& Dai, 2007). Most Chinese torreya trees grow at remote sites. There are limited highways, county roads and transportation to reach these locations. Since the Chinese torreya trees are tall, it is also dangerous to pick up seeds, especially for those trees living at steep slope areas. Local young people would like to live and work in cities (People's Government of Shaoxing City, 2013). In the early time, there was outmigration in an attempt to have a better life, which is similar with other mountainous areas (Molden, Breu, van Dach, Zimmermann, \& Mathez-Stiefelet, 2017).

- Lack of knowledge: Most farmers don't have sufficient knowledge for diseases and pest management on Chinese torreya trees. They often overuse fertilizer in order to gain more seed production, and it greatly affect these old Chinese torreya trees, such as those of more than a thousand year old trees. Local people once cut down large amount of male trees for timber only because these trees don't produce seeds. This led to insufficient pollination and low seed production at a regional level. Furthermore, high quality seed resources are being threatened or disappearing due to tree aging and disturbances, so the establishment of protection measures is very necessary (Chen \& Jin, 2019; People's Government of Shaoxing City, 2013).

\section{Theoretical Approach and Data}

Based on the above challenges, it seems hard for local people to make more profit from the nuts production at the current Chinese torreya forests unless more plantations are established. More plantations of Chinese torreya will affect other land-use and their ecological functionalities. The local policy makers faced the similar dispute over whether conservation and policies should prioritize biodiversity and landscape conservation or poverty alleviation and human livelihood improvement. However, sustainable intensification of agriculture emphasizes multifunctionalities of agro-ecosystems and its goal is to minimize environmental impacts but also to raise productivity. Thus, through collaboration of stakeholders, scientists and decision makers, the local society has been exploring 
the multi-functionalities of Chinese torreya forest with the goal of gaining more income and minimizing environmental impacts. This strategy is well achieved through the procedures suggested by translational ecology (Figure 4). The traditional ecological approach with a goal to have more income is improved by adding cultural and eco-tourism factors, and even the recent development of biomedical use for Chinese torreya (Figure 5). It appears that this strategy is suitable to the local society and economy. With the data collected from local agencies, some aspects of local society, economy and ecological multi-functionalities are explored.

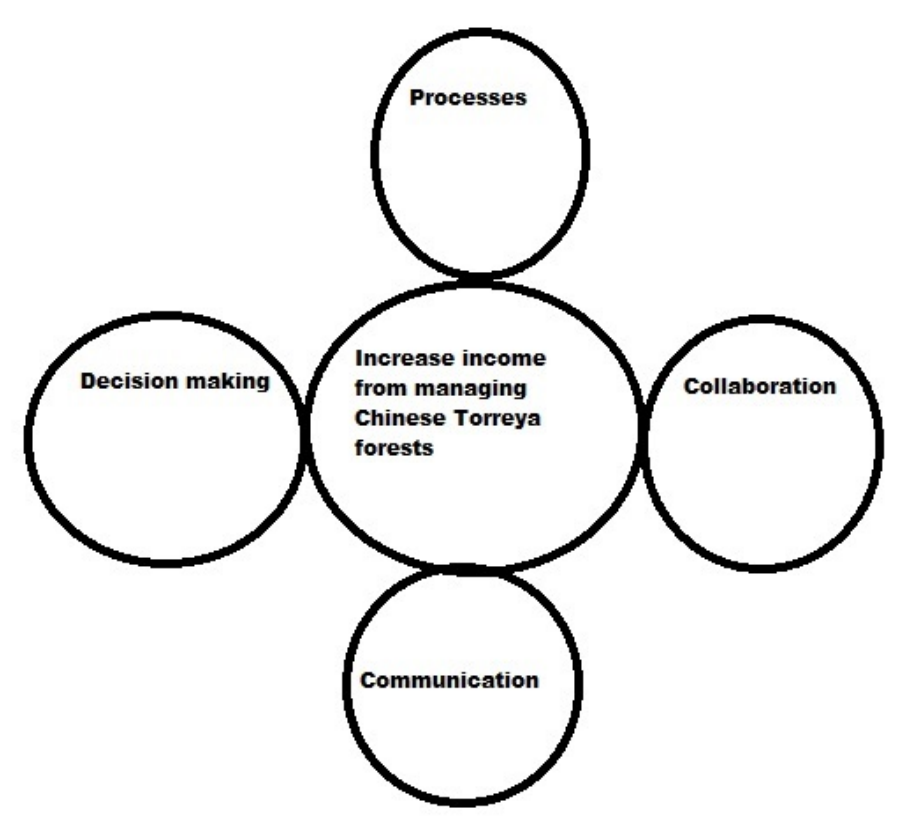

Figure 4. Diagram of using translation ecology in developing economy of Chinese torreya forests. (Decision making: refers to decisions in cultural, environmental, economic, and legal opportunities; Collaboration: interdisciplinary partnership; Communication: long-term conception to implementation; Processes: integrative representation of all stakeholders) (adapted from Enquist et al. 2017)

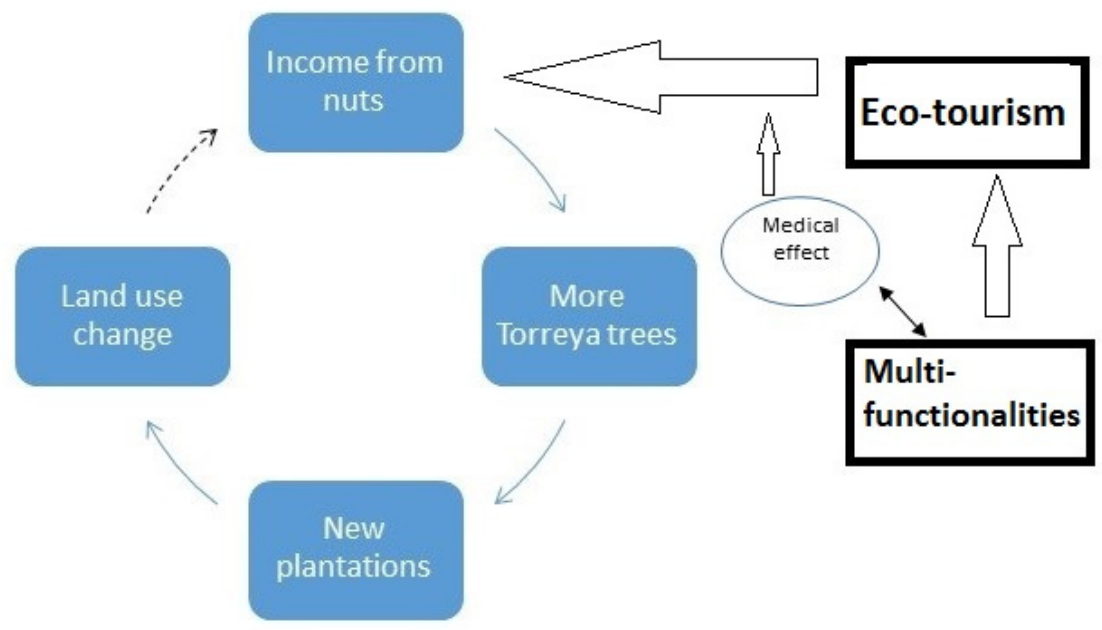

Figure 5. An improved approach to increase the income from Chinese torreya plantations based on sustainable intensification of agriculture and translational ecology (solid line with arrow means possible and dot line with arrow means uncertainty) 


\section{Multi-Functionalities of Chinese Torreya Forests}

\subsection{Culture and Social Function}

Because of the unique features in Chinese torreya trees, such as long lifespan (more than a thousand year), dioecism, and the ability to grow two generations of fruits on a single branch, Chinese torreya trees symbolize the meaning of "longevity, happiness, and reunion", which melted into every aspect of the local social culture (People's Government of Shaoxing City, 2013; Wang \& Ming, 2015). Through the inheritance of torreya culture in the long history, the social history and cultural memories, such as family values, local history and social rituals, are blended together and remembered as a whole, which leads to the formation of a distinguished social identity and cultural consciousness at the local society. This culture could attract people from other regions to visit torreya forests and this unique environment. During the past 10 years, the number of people visited the Chinese Torreya Park every year increased from the original about 50,000 to 600,000 at the current (Figure 6).

There are lot of poems, calligraphies, literature, paintings, proverbs, drama, and songs related to Chinese torreya throughout history, such as many famous Chinese writers (e.g., Su Shi, Ye Shi, and Mei Yaochen) expressed their appreciation of Chinese torreya in their historical masterpieces (People's Government of Shaoxing City, 2013). Legendary fiction (Journey to the West) also mentions the values of Chinese torreya. All the legends and stories associated with Chinese torreya are preserved by the local society (Wu, 2013). Some people like to record the beauty and legends of Chinese torreya by using pictures, paintings, drama and also folk songs. The current annual torreya festival promotes the development of related art and sports performance, social communication and commercial activities.

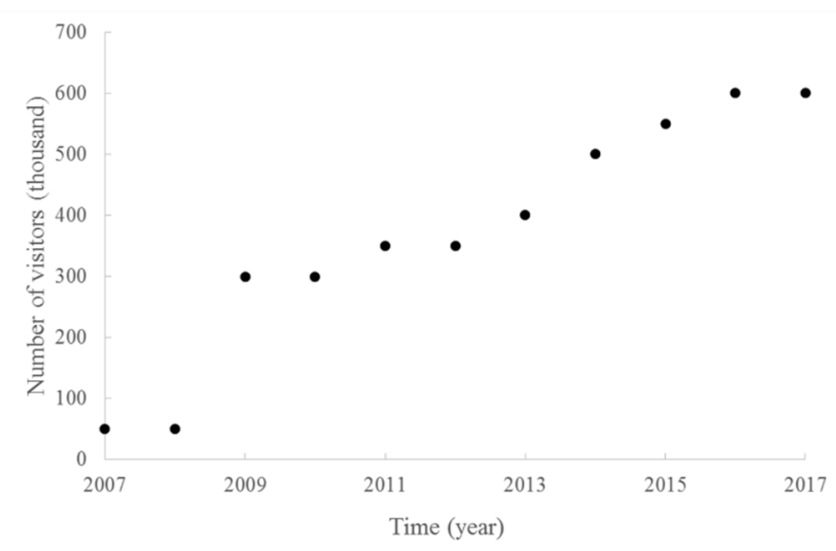

Figure 6. The number of people visited the Torreya Forest Park at Zhuji every year

Due to the long life span and also beautiful tree shape, Chinese torreya forests are often a popular place for wedding ceremonies. As a nutritious, valuable and rare dry fruit, Chinese torreya and its food products usually serve as precious gifts. Many blessings and sacrificial ceremonies have resulted from the beautiful wishes of "high production" and "safety". Some local farmers have festivals every January (lunar calendar) to wish for high production of Chinese torreya. Also, before seed harvesting in every year, some villages and families would organize different types of worship to wish for safety during harvesting (e.g., climbing tree to pick up fruits) (People's Government of Shaoxing City, 2013).

Some special social activities are also shown in the history and setting of local houses and communities. Now a few old houses, ancestral halls, schools, and villages established in the Ming and Qing Dynasty are preserved for tourists by the cultural protection agencies. The total related commercial value of Chinese torreya in Zhuji County increased from about $\$ 33$ million per year to $\$ 0.12$ billion per year during the past 10 years (Figure 7). 


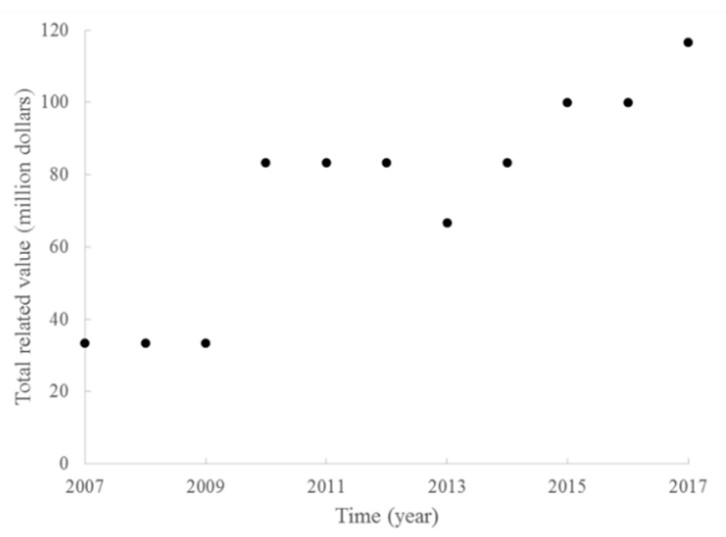

Figure 7. The total related value with Chinese torreya at Zhuji in the past 10 years

\subsection{Environmental Function}

Due to the big tree canopies and high leaf area, Chinese torreya forests have the lowest soil erosion in comparison with other tree plantations. The annual water conservation of ancient torreya forests is much high $(1,026.3 \mathrm{tons} / \mathrm{ha})$ than a timber forest of China fir (34.20 tons/ha). The powerful water conservation may be from its canopy interception, defoliated leaves, and soil, which usually contains high levels of organic matter (Chen \& Jin, 2019; People's Government of Shaoxing City, 2013). Further, the local people at Chinese torreya forest areas seemed to have a much longer lifespan than the people from the other areas in the same region. For example, the average percentages of old people in $60,70,80$ and 90 years old were $15.5 \%, 7.1 \%, 2.4 \%$, and $0.2 \%$ in the other part of Shaoxing region, but the corresponding percentages at Zhaojiazhen, which is located in Chinese torreya forest area, were 21.6\%, 10.2\%, 3.2\%, 0.3\%, respectively (People's Government of Shaoxing City, 2013; Wang \& Ming 2014). This might be related to local environmental condition and life style.

\subsection{Functional Food}

Local people have used the processed nuts of Chinese torreya as food for a long time (Li \& Dai, 2007). The nuts are something with special color, smell, and taste. Its nutrients include protein, unsaturated fat, amino acids, minerals and vitamins (Chen \& Jin, 2019; Li \& Dai, 2007). The nuts could be used to produce varieties of food, such as cakes, candy, and shortbread after being fried, and also drinks (wine and juice). Torreya oil can selectively decrease serum total cholesterol and glycerin trilaurate, and increase high density serum lipoprotein cholesterol. The four types of lipo-alkaloids can suppress lymphatic leukemia and is beneficial to the prevention and treatment of malignant lymphosarcoma (Chen \& Jin, 2019). These products are very popular and always be exported to international markets (People's Government of Shaoxing City, 2013).

An overall evaluation of the agricultural muti-functionalities of Chinese torreya forests was conducted and there were high values in agro-cultural bequeathment function and environmental protection function (Xu et al., 2013). With the development of these multi-functionalities of Chinese torreya forests, ecotourism has been greatly promoted. Every year thousands of people visit museums, Torreya Forest Park and some historic sites. The annual torreya festival provides a good platform for people to meet, celebrate and also explore business opportunities. This greatly drives the development of local economy and increase the consumption of torreya nuts. Currently, there are big development in some medical products, because the seeds possess anti-oxidative and acute antiinflammatory properties (Chen et al., 2006), the value of products reaches about 10 times of the original one. More and more local people got rich by developing business related to Chinese torreya forests and its products. The local population not only changed from out-migration to in-migration, but also the business development empowers women in the local society. Traditional gender roles limited women to participate in labor intensive forest management (Gratzer \& Keeton, 2017), such as managing Chinese torreya forests or picking up fruits. However, currently the development related to cultural activities, eco-tourism, service, and less labor intensive jobs is greatly changing the inequality between men and women.

\section{Conclusions}

In order to eradicate poverty and hunger and contribute to human wellbeing, tree plantations are usually developed to increase plant productivity under intensive management and exclude the competition from other species. But under the context of maintaining the resilience of local landscape to biodiversity and rapid global environmental change and also satisfying human needs, a paradigm shift to sustainable intensification of agriculture should be 
enhanced by exploring the multi-functionalities and with less environmental impacts. With the guideline of sustainability, scientists, stakeholders, and policy makers need to deliberately engage to consider the practices which show the most promise and potential pitfalls of those practices. Here the case study of Chinese torreya in Zhuji County of China is analyzed. Based on the traditional thinking, more plantations of Chinese torreya should be established in order to gain more profit. By understanding the social and cultural function of Chinese torreya forests, local government and communities have developed multi-functionalities of this Chinese torreya forest landscape to achieve the same goal in a sustainable way although some technical support and environmental education to farmers are urgently needed. Under the age of dealing with the conflict between economic development, social inequality and ecological services, it is necessary to use the latest science, such as knowledge from translational ecology and sustainable intensification of agriculture, to build the relationships with scientists, stakeholders and policy makers and implement relevant actions. The ideas and approach from this case study can be applied for sustainable development at other plantations (e.g., oil palm) in other regions.

\section{Acknowledgements}

This research was partially supported by USDA Mc-Stennis project (1008643) and Shaoxin330.

\section{References}

Belay, M., Edwards, S., \& Gebeyehu, F. (2005). Culture as an expression of ecological diversity. Mountain Research and Development, 25, 10-14. https://doi.org/10.1659/0276-4741(2005)025[0010:CAAEOE] 2.0.CO;2

Chen, B. Q., Cui, X. Y., Zhao, X., Zhang, Y. H., Piao, H. S., Kim, J. H.,...Yun, Y. P. (2006). Antioxidative and acute anti-inflammatory effects of Torreya grandis. Fitoterapia, 77, 262-267. https://doi.org/10.1016/j. fitote.2006.03.019

Chen, X., \& Jin, H. (2019). Review of cultivation and development of Chinese torreya in China. Forests, Trees, \& Livelihoods, 28, 68-78. https://doi.org/10.1080/14728028.2018.1553690

Conway, G. (1997). The doubly green revolution: Food for all in the twenty-first century. Ithaca, NY: Comstock Publishing Associates.

Enquist, C. A. F., Jackson, S. T., Garfin, G. M., Davis, F. W., Gerber, L. R., Littell, J. A., ... Shaw, M. R. (2017). Foundations of translational ecology. Frontiers in Ecology and the Environment, 15, 541-550. https://doi.org/10.1002/fee.1733

Foley, J. A., DeFries, R., Asner, G. P., Barford, C., Bonan, G., Carpenter, S. R., ... Snyder, P. K. (2005). Global consequences of land use. Science, 309, 570-574. https://doi.org/10.1126/science.1111772

Gratzer, G., \& Keeton, W. S. (2017). Mountain Forests and Sustainable Development: The Potential for Achieving the United Nations' 2030 Agenda. Mountain Research and Development, 37, 246-253. https://doi.org/10.1659/MRD-JOURNAL-D-17-00093.1

Grêt-Regamey, A., Brunner, S. H., \& Kienast, F. (2012). Mountain ecosystem services: who care? Mountain Research and Development, 32, S23-S34. https://doi.org/10.1659/MRD-JOURNAL-D-10-00115.S1

Godfray, H. C. J., \& Garnett, T. (2014). Food security and sustainable intensification. Philosophical Transactions of the Royal Society B, 369, 20120273. https://doi.org/10.1098/rstb.2012.0273

IPCC. (2014). Climate change 2014: Impacts, adaptation, and vulnerability. In Field et al., (ed.), Part A: Global and sectoral aspects. Contribution of working group II to the fifth assessment report of the intergovernmental panel on climate change. New York, NY: Cambridge University Press.

Jackson, L. E., Puleman, M. M., Brussaard, L., Bawa, K. S., Brown, G. G., Cardoso, I. M., ...van Noordwijk, M. (2012). Social-ecological and regional adaptation of agrobiodiversity management across a global set of research regions. Global Environmental Change, 22, 623-639. https://doi.org/10.1016/j.gloenvcha. 2012.05.002

Jackson, S. T., Garfin, G. M., \& Enquist, C. A. F. (2017). Toward an effective practice of translational ecology. Frontiers in Ecology and the Environment, 15, 540. https://doi.org/10.1002/fee.1738

Li, Z. J., \& Dai, W. S. (2007). Chinese Torreya. Beijing, China: Science Press.

Molden, D., Breu, T., van Dach, S. W., Zimmermann, A. B., Mathez-Stiefelet, S.-L. (2017). Focus issue: Implications for out- and in-migration for sustainable development in mountains. Mountain Research and Development, 37, 387. https://doi.org/10.1659/mrd.3704 
Pardey, P. G., Beddow, J. M., Hurley, T. M., Beatty, T. K. M., \& Eidman, V. R. (2014). A bounds analysis of world food futures: Global agriculture through to 2050. Australian Journal of Agricultural and Resource Economics, 58, 571-589. https://doi.org/10.1111/1467-8489.12072

People's Government of Shaoxing City. (2013). Kuanjishan Ancient Chinese Torreya Community. Proposal for Global Important Agricultural Heritage System Initiative. Shaoxin, Zhejiang Province, China.

Rockström, J., Williams, J., Daily, G., Noble, A., Matthews, N., Gordon, L., ... Bird, J. (2017). Sustainable intensification of agriculture for human prosperity and global sustainability. Ambio, 46, 4-17. https://doi.org/10.1007/s13280-016-0793-6

Shrestha, S., \& Medley, K. E. (2017). Integrating ecological and ethnobotanical knowledge to promote collaborative conservation planning in the Nepal Himalaya. Mountain Research and Development, 37, 97107. https://doi.org/10.1659/MRD-JOURNAL-D-15-00081.1

Steffen, W., Crutzen, P. J., \& McNeill, J. R. (2007). The Anthropocene: Are humans now overwhelming the great forces of nature? Ambio, 36, 614-621.

Tilman, D., Fargione, J., Wolff, B., D’Antonio, C., Dobson, A., Howarth, R., ... Swackhamer, D. (2001). Forecasting agriculturally driven global environmental change. Science, 292, 281-284. https://doi.org/10. 1126/science. 1057544

Tittonell, P. (2014). Ecological intensification of agriculture-Sustainable by nature. Current Opinion in Environmental Sustainability, 8, 53-61. https://doi.org/10.1016/j.cosust.2014.08.006

United Nations Secretary-General's High-level Panel on Global Sustainability. (2012). Resilient people, resilient planet: A future worth choosing. Report for the 2012 Rio 20 Earth summit, New York.

Xu, Y.-T., Min, Q.-W., Bao, Y.-Y., Yuan, Z., Wang, B., He, L., \& Chen, J.-Y. (2013). Evaluation of agricultural multi-functional value of the living ancient Torreya grandis community in Kuaiji Mountain. Journal of Ecology and Rural Environment, 29, 717-722. (in Chinese with English abstract)

Wall, T. U., McNie, E., \& Garfin, G. M. (2017). Use-inspired science: making science usable by useful to decision makers. Frontiers in Ecology and the Environment, 15, 551-559. https://doi.org/10.1002/fee.1735

Wang, B., \& Ming, Q.-W. (2015). Zhejiang Shaoxing Kuaijishan Guxiangfeiqun. Beijing, China: China Agricultural Press. (in Chinese)

Wu, S. T. (2013). Chinese Torreya legends. Hangzhou, China: Xiling Seal Engraver's Society's Publishing House. (in Chinese)

\section{Copyrights}

Copyright for this article is retained by the author(s), with first publication rights granted to the journal.

This is an open-access article distributed under the terms and conditions of the Creative Commons Attribution license (http://creativecommons.org/licenses/by/4.0/). 